\title{
Research Study:
}

\section{Feasibility and effectiveness of Ida Telecare tools for NHS Audiology}

\author{
patients
}

\section{We invite you to take part in a research study}

- We would like to invite you to take part in our research study that aims to assess the whether patients can access and use online tools to help them prepare for audiology appointments, and whether these benefit patients.

- Before you decide to take part, we would like you to understand why the research is being done and what it would involve for you.

- Please read the following information carefully. You might also like to discuss it with family or friends.

- Ask us if there is anything that is not clear or if you would like more information. Take time to decide whether or not you wish to take part.

\section{Contents}

1. What is the purpose of the study?

2. Why have I been asked to take part?

3. Do I have to take part in this study?

4. What will happen if I take part in the study?

5. What are the possible disadvantages of taking part?

6. What are the possible benefits of taking part?

7. What happens to the results of the research study?

8. Who is organising and funding the study?

9. Who has reviewed the study?

10. Will my results be kept confidential?

11. Who do I speak to if problems arise?

\section{How to contact us}
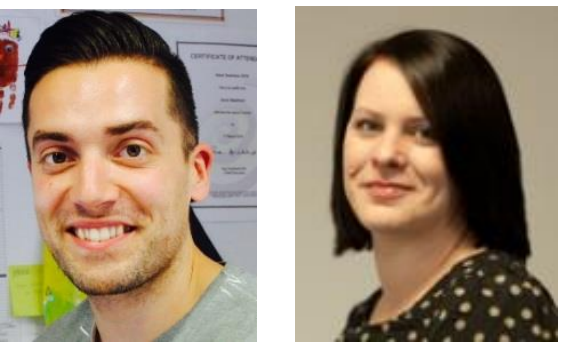

You are encouraged to ask any questions you wish, before, during or after the study.

If you would like to discuss the research or have any concerns while taking part please contact $\mathrm{Dr}$ David Maidment or Dr Helen Henshaw, our researchers.

\section{Address:}

NIHR Nottingham Biomedical Research Centre, Ropewalk House, 113 The Ropewalk, Nottingham, NG1 5DU.

Tel: $+44(0) 1158232600$

Fax: $+44(0) 1158232618$

Email: mszhlh@nottingham.ac.uk mszdm@nottingham.ac.uk

Web: www.hearing.nihr.ac.uk 


\section{What is the purpose of this study?}

By allowing patients to think about their hearing challenges and communication needs prior to audiology appointments, discussions with the audiologist can be best used. Better informed conversations may enable patients' needs to be addressed more quickly and more thoroughly.

The Ida Institute has developed a range of easy-touse online tools that are designed to help people with hearing loss prepare for audiology appointments, make important decisions related to their hearing healthcare, and successfully manage their everyday communication. Patients who make choices that are right for them during their hearing appointments (such as obtaining a hearing aid, or not), are more likely to live well with their hearing loss. In this study we will assess how people attending an NHS audiology clinic use the Ida telecare tools and assess the benefits of one of the tools to improve patient outcomes.

\section{Why have I been asked to take part?}

We are looking for people with hearing loss who have been invited to attend an audiology appointment to take part.

You are eligible to take part in this study if you:

- Are 18 years of age or over

- Have good understanding of written and spoken English

- Have access to the internet

- Have not used hearing aids before

\section{Do I have to take part in this study?}

No. It is up to you to decide whether or not to take part. If you decide to take part you will be asked to sign a consent form to confirm that you understand what is involved when taking part in this study. If you decide to take part you are free to leave the study at any time and without giving a reason. If you withdraw, unless you object, we will still keep records relating to the intervention given to you, as this is valuable to the study. A decision to withdraw at any time, or a decision not to take part, will not affect the quality of care you receive.

\section{What will happen if I take part in the study?}

If you decide to take part, you will be provided with a link to access Ida Telecare tool(s) online. You will be asked to complete the tool(s) and send them to the research team at the NIHR Nottingham Biomedical Research Centre (PDF file by email or post). You can take these along to discuss with your audiologist. Some of these sessions may be video recorded and shared with the research funders to help improve the tools. You may also be asked to complete several questionnaires at home, either online or by post. The questionnaires will take up to 45 minutes to complete and you may be asked to do this up to 3 times over a 12 week period.

A small group of individuals will also be invited to the NIHR Nottingham Biomedical Research Centre at Ropewalk House to complete the tools with a researcher, or to discuss your views of the tools. These sessions should last no more than 1.5 hours. There will normally be one researcher who you will meet. We will video record use of the tools and audio record any discussions to make sure that we have an accurate record of events.

Audio recordings will be transcribed. All recordings (video and audio) and audio transcripts will be confidential and stored securely for a maximum of 18 months before being destroyed. There are no right or wrong answers; the important thing is for you to express your personal opinions. You will be given opportunities to take breaks and to have refreshments.

Reasonable travel expenses (up to £10) will be paid at the end of each visit. We will also pay you an inconvenience allowance of $£ 5.00$ per hour. If you decide to take part in the study, you must report any problems via the contact details provided on page 1 of this information sheet. In the unlikely event of an emergency, we may contact your nominated next of kin. 


\section{What are the possible disadvantages of taking part?}

We do not anticipate any disadvantages or risks to taking part in this study. If you have any concerns after your participation in the study, we would be happy to discuss these with you.

\section{What are the possible benefits of taking part?}

We cannot promise that the study will help you but the telecare tools might help patients prepare for audiology appointments. The information we get from this study will help us design future studies that could benefit other people with hearing loss.

\section{What happens to the results of the research study?}

The results of the study will be available after it finishes and will usually be published in a medical journal or be presented at a scientific conference. The data will be anonymous and none of the patients involved in the study will be identified in any report or publication.

\section{Who is organising and funding the study?}

The Nottingham University Hospitals NHS Trust will act as sponsor for the research. The Ida Institute will fund the research.

\section{Who has reviewed the study?}

All research in the NHS is looked at by an independent group of people called a Research Ethics Committee, to protect your safety, rights, well-being and dignity. This study has been reviewed and given a favourable opinion by the NHS South Central - Oxford C Research Ethics Committee. The study has also been reviewed and approved by the Research \& Innovation department of Nottingham University Hospitals NHS Trust.
All the information about your participation in this study will be kept confidential.

If you consent to take part in this study, the records obtained while you are in this study as well as related health records will remain strictly confidential at all times. The information will be held securely on paper and electronically at the NIHR Nottingham Biomedical Research Centre at Ropewalk House under the provisions of the 1998 Data Protection Act.

Your name will not be passed to anyone else outside the research team. You will be allocated a study number, which will be used as a code to identify you on all study forms.

Your relevant medical and research records will be available to the research team but may also need to be made available to people authorised by the Research Sponsor, which is the organisation responsible for ensuring that the study is carried out correctly. A copy of your consent form may be sent to the Research Sponsor during the course of the study. By signing the consent form you agree to this access for the current study and any further research that may be conducted in relation to it, even if you withdraw from the current study.

If you withdraw consent from further study, unless you object, your data will remain on file and will be included in the final study analysis.

If you consent, but lose capacity to consent during the study, you will be withdrawn from the study. Data already collected with consent will be retained and used in the study. No further data will be collected or any other research procedures carried out on or in relation to you.

In line with Good Clinical Practice guidelines, at the end of the study, your data will be securely archived for a minimum of 15 years. Arrangements for confidential destruction will then be made. 


\section{Who do I speak to if problems} arise?

If you have a concern about any aspect of this study, you should contact the Principal investigator, Dr Helen Henshaw, using the address and telephone number on page 1 or this email: helen.henshaw@.nottingham.ac.uk.

If you remain unhappy and wish to complain formally, you can do this through the NHS Complaints Procedure. Details can be obtained from the hospital or you can contact PALS (Patient Advice and Liaison Service) telephone 08001830204 .

In the event that something does go wrong and you are harmed during the research study there are no special compensation arrangements. If you are harmed and this is due to someone's negligence then you may have grounds for a legal action for compensation but you may have to pay your legal costs. The normal National Health Service complaints mechanisms will still be available to you.

Thank you for taking the time to read this information sheet and consider this study.
Where to find us

Parking

Pay-and-display parking is available immediately outside the main building with additional pay-anddisplay parking in nearby streets. There are also free disabled parking spaces outside the main building. Parking is limited to a maximum of two hours.

\section{Public Transport}

There are no bus stops directly outside Ropewalk House, however the building is in the centre of Nottingham, with public transport links nearby.

The nearest bus stops are on Toll House Hill and Maid Marian Way. There is access via a less steep hill from the bus stops on Canning Circus.

People with restricted mobility may consider travelling to appointments using one of the many community transport schemes operated across the county.

\section{On arrival at Ropewalk House}

The NIHR Nottingham Biomedical Research Centre is situated in the mezzanine floor of Ropewalk House. On entering the foyer at ground level, follow the red signs for NIHR Nottingham Biomedical Research Centre. There is a lift. Disabled clients who require assistance at Ropewalk House to access the basement should telephone 01158232600 in advance to make appropriate arrangements.

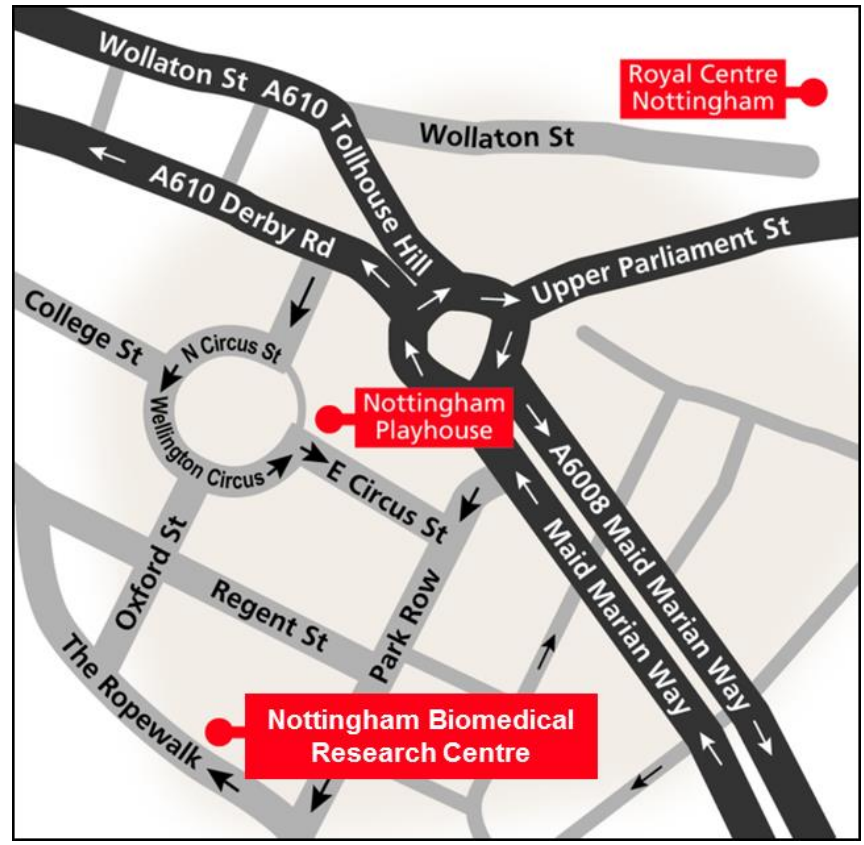

